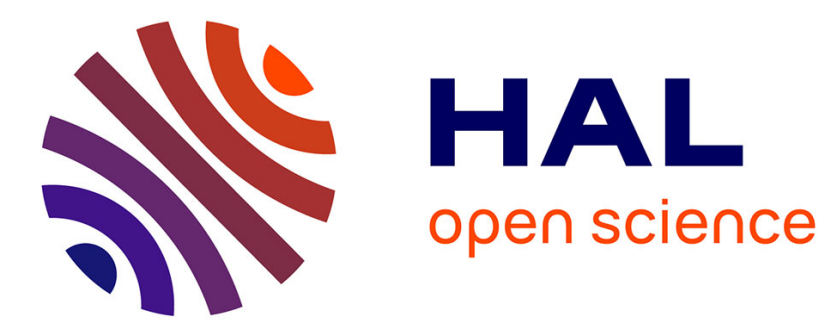

\title{
Flame Quenching at Walls: A Source of Sound Generation
}

\author{
Abdulla Ghani, Thierry Poinsot
}

\section{To cite this version:}

Abdulla Ghani, Thierry Poinsot. Flame Quenching at Walls: A Source of Sound Generation. Flow, Turbulence and Combustion, 2017, vol. 99 ( $\mathrm{n}^{\circ}$ 1), pp. 173-184. 10.1007/s10494-017-9810-5 . hal01548373

\section{HAL Id: hal-01548373 \\ https://hal.science/hal-01548373}

Submitted on 27 Jun 2017

HAL is a multi-disciplinary open access archive for the deposit and dissemination of scientific research documents, whether they are published or not. The documents may come from teaching and research institutions in France or abroad, or from public or private research centers.
L'archive ouverte pluridisciplinaire HAL, est destinée au dépôt et à la diffusion de documents scientifiques de niveau recherche, publiés ou non, émanant des établissements d'enseignement et de recherche français ou étrangers, des laboratoires publics ou privés. 


\section{Open Archive TOULOUSE Archive Ouverte (OATAO)}

OATAO is an open access repository that collects the work of Toulouse researchers and makes it freely available over the web where possible.

This is an author-deposited version published in : http://oatao.univ-toulouse.fr/ Eprints ID : 17942

To link to this article : DOI:10.1007/s10494-017-9810-5

URL : http://dx.doi.org/10.1007/s10494-017-9810-5

To cite this version : Ghani, Abdulla and Poinsot, Thierry Flame Quenching at Walls: A Source of Sound Generation. (2017) Flow Turbulence and Combustion, vol. 99 ( $\left.\mathrm{n}^{\circ} 1\right)$. pp. 173-184. ISSN 13866184

Any correspondence concerning this service should be sent to the repository administrator: staff-oatao@,listes-diff.inp-toulouse.fr 


\title{
Flame Quenching at Walls: A Source of Sound Generation
}

\author{
Abdulla Ghani ${ }^{1}$. Thierry Poinsot $^{2}$
}

\begin{abstract}
This paper presents a numerical study of head on quenching (HOQ) (an extreme case of flame/wall interactions) as a source of sound generation, which in turn can trigger combustion instabilities and enhanced noise levels. High-fidelity numerical simulations are performed to investigate the impact of wall temperature, high chamber pressures and Lewis number of the fuel on the noise generation. It is demonstrated by theory and simulations that the underlying mechanism of sound generation is flame surface destruction (flame annihilation). Special emphasis is put on chemical modeling where simple and complex mechanisms were compared: it is shown that simple chemistry simulations overestimate the generated pressure peaks due to a too fast extinction of the heat release rate compared to the complex scheme. In contrast to the simple mechanism, the complex scheme accounts for minor and intermediate species production and destruction which slows down the extinction process and thus lead to a lower sound level. This effect has to be taken into account, especially in the context of Large Eddy Simulation (LES) of combustion instabilities and combustion noise where simple chemical descriptions are often employed.
\end{abstract}

Keywords Head on quenching $\cdot$ Noise generation $\cdot$ Chemistry modeling

\section{Introduction}

Modern combustion systems are not only underlying restrictions as low noise and pollutant emission but also compact combustion chamber design. High confinement ratios raise

Abdulla Ghani

ghani@tfd.mw.tum.de

1 Thermo-Fluid Dynamics Group, Technical University of Munich, Boltzmannstr. 15, 85747

Garching, Germany

2 CNRS - IMFT, 1 Allée du Professeur Camille Soula, Toulouse 31400 Cedex, France 
questions concerning interactions between flames and walls. Flame/wall interactions have already been investigated in many studies for heat transfer questions [1-5] but have not been yet considered as a source of direct combustion noise. The noise generation has a direct influence on the system stability since pressure fluctuations generate heat release modulations, which are known to trigger combustion instabilities [6, 7].

The most extreme case of flame/wall interaction is head on quenching (HOQ): the flame propagates at its laminar speed perpendicular to the wall and extinguishes at the wall. Most flame/wall interaction studies have investigated the distance of flame quenching, heat flux to the wall or the formation of hydrocarbons [8-10]. The generation of direct combustion noise due to HOQ has not been reported before although representing an important canonical test case. These transient combustion processes (flame ignition and extinction) need to be characterized in terms of sound generation as recently concluded by Ihme et al. [11]. Here, Direct Numerical Simulation (DNS) is used with the objective to identify flame quenching at walls as a source of noise. We will study HOQ for a wide range of relevant scenarios: various wall temperatures, combustion chamber pressures and fuel mixtures (represented by the Lewis number).

Chemistry modeling plays a significant role in the description of flame/wall interaction. Bruneaux et al. [8] showed that simple chemistry modeling using one reaction mechanism overestimates the wall heat fluxes during HOQ while a complex scheme with 52 reactions agreed better with experimental results. Westbrook et al. [10] investigated the formation of hydrocarbons employing detailed chemistry. In comparison to single-step chemistries, it was found that laminar flame speeds and flame thicknesses are not correctly reproduced by the simple schemes and lead to overestimated unburnt hydrocarbon contents. This study will highlight the effect of chemical kinetics modeling on the sound generation. For this, two chemistry mechanisms are utilized: a global scheme (called BFER) with 6 species and 2 reactions [12] which is here referred to as simple chemistry. These simple schemes are often employed in LES due to their low computational cost and the correct reproduction of laminar flame speeds and adiabatic flame temperatures over a wide range of equivalence ratios and pressures for gaseous $[13,14]$ and liquid fuels $[15,16]$. The 'complex' scheme (called LU19) is an analytically reduced chemistry using 19 transported species and 11 species using Quasi Steady State approximation (QSSA) (Section 3). These mechanisms show significant differences in the generation of pressure fluctuations, something which has not been reported before. This study highlights the importance of correct chemistry modeling for future combustion instability and combustion noise studies. Besides, the flame/wall interactions are identified as a source of noise over a wide range of important applications.

The paper is organized as follows: modeling of sound generation by flame surface destruction is briefly recapitulated following the ideas of Talei et al. [17] (Section 2). Then, the numerical setup is presented in Section 3 followed by Section 4, validating the DNS against classical HOQ studies in terms of quenching distance and wall heat flux. The different scenarios of HOQ and the corresponding noise levels are presented in Section 5 .

\section{Modeling of Sound Generation by Premixed Flame Annihilation}

The head on quenching process is characterized by flame quenching at the wall. Obviously, the perturbation of flame surface plays a significant role in the description of the sound gene ration [18-22]. Starting from the work of Lighthill [23] and its reformulation by Dowling 
(Chapter 13 in [24]), it was shown by Talei et al. [17] that far-field pressure fluctuations for one-dimensional, completely annihilated flames can be expressed by:

$$
p^{\prime}=-\rho_{u} c_{b}\left(1-\frac{T_{u}}{T_{b}}\right) s_{L}
$$

Interestingly, Eq. 1 depends only on the fresh gas density $\rho_{u}$, the sound speed in the burnt gases $c_{b}$, the laminar flame speed $s_{L}$ and the temperatures in the unburnt and burnt gases $T_{u}$ and $T_{b}$, respectively. These variables can be easily obtained by one-dimensional solvers allowing a simple and fast determination of the pressure fluctuation. For Section 5, freely propagating, one-dimensional adiabatic flames were computed using CANTERA with the GRI-MECH 3.0 mechanism to feed Eq. 1.

\section{Numerical Settings}

The fully-compressible reacting multi-species Navier-Stokes equations are solved directly using the AVBP code. A two-step Taylor-Galerkin convection scheme provides fourth order accuracy in time and space Colin et al. [25] on structured meshes. It has excellent dispersion and dissipation properties and is characterized by its high spectral resolution. The outlet is treated as non-reflective using Navier-Stokes Characteristic Boundary Conditions (NSCBC) [26]. Top and bottom boundaries were set as symmetric so that the domain can be considered as $1 \mathrm{D}$ (Fig. 1). The wall temperature is varied in a range of temperatures from 300 to $900 \mathrm{~K}$ in 3 steps.

Chemistry for methane/air combustion is described by two different mechanisms: one is the analytical mechanism of [27] using 19 transported species and 11 QSSA species and 15 reactions (called complex chemistry LU19). QSSA allows a simplification of the chemical kinetic system by assuming that concentrations of intermediate species remain constant in time. As a result, the QSSA species concentrations are obtained by solving an algebraic equation instead of differential equations [28], reducing the number of transported species. The Prandtl number is constant $(P r=0.7)$ whereas each species has its Schmidt number. This scheme has been validated against the GRI-MECH 3.0 mechanism using CANTERA in terms of flame speed, adiabatic flame temperature and major species (Fig. 2 right). The full GRI-MECH 3.0 scheme contains 53 species and 325 reactions and is referred to as the full chemistry. The simple mechanism (called BFER) is a globally reduced one, using 6 species and 2 reactions which do not capture the detailed physics of the complex chemistry [12]. Generally, simple chemistries are fitted to retrieve basic flame characteristics such as the laminar flame speed and the adiabatic flame temperature but fail in the correct reproduction

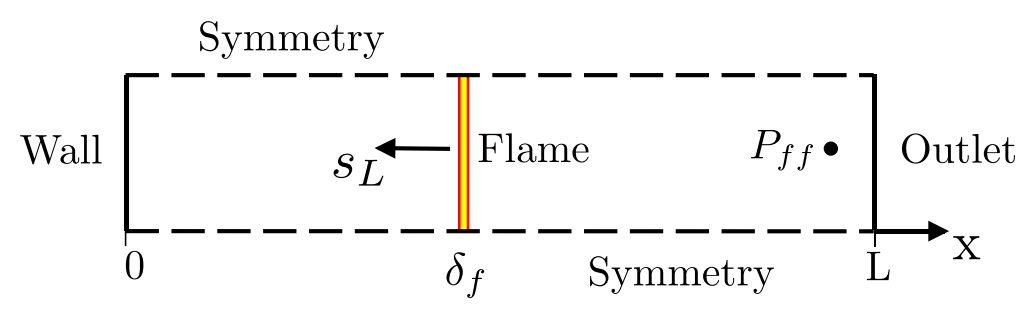

Fig. 1 Sketch of the one-dimensional domain 

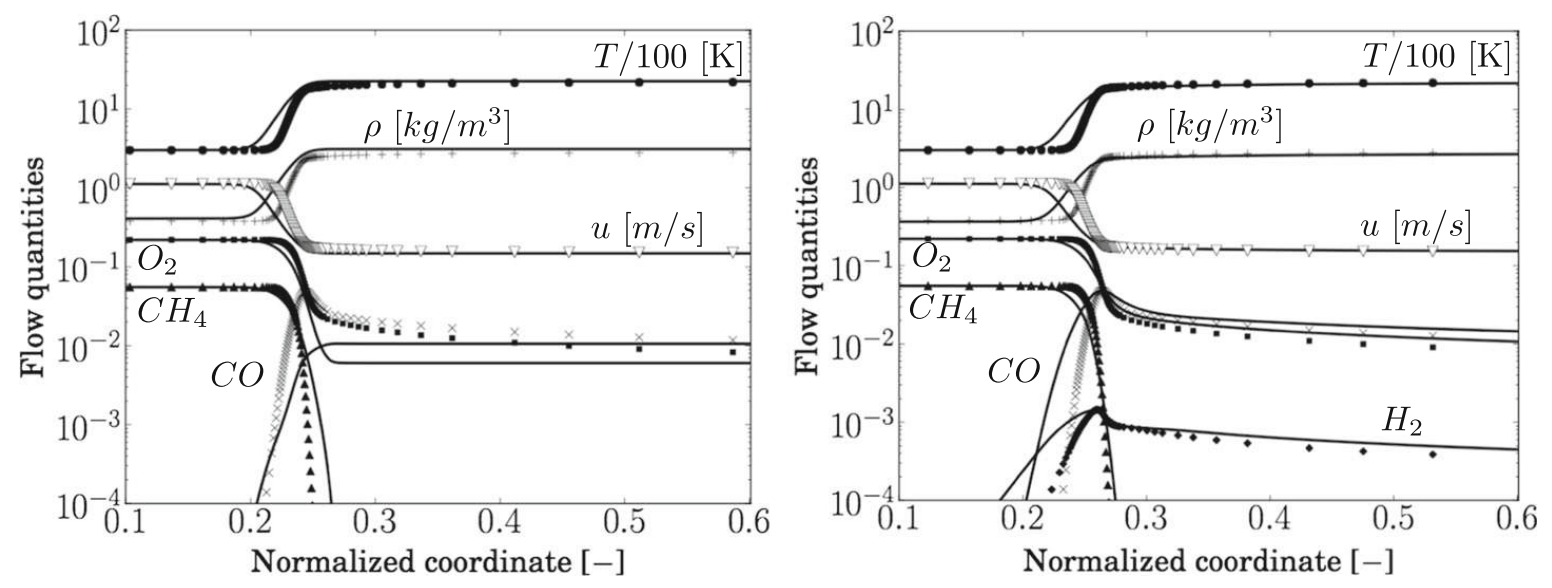

Fig. 2 Profiles of adiabatic flame temperature (divided by 100), flame speed, density and species mass fractions of a freely propagating stoichiometric flame. Left: Comparison between CANTERA with GRI-MECH 3.0 (lines) and DNS with simple chemistry BFER (symbols). Right: Comparison between CANTERA with GRI-MECH 3.0 (lines) and DNS with complex chemistry LU19 (symbols)

of radicals (Fig. 2 left). These mechanisms are preferred in the context of LES because of their low computational cost.

The one-dimensional domain is discretized with 6400 nodes in the axial direction $(L=$ $0.01 \mathrm{~m}$ ) and 2 nodes in the transverse direction using cartesian elements. The mesh resolution has been chosen so that the generated pressure fluctuation is mesh independent. All simulations contain at least 40 points in the flame front. The far-field pressure fluctuations are recorded at $x / L=0.9$ (probe $P_{f f}$ in Fig. 1) for all cases.

Since HOQ is a transient process, the initialization has to be done carefully. First, the reacting flow is established in the $1 \mathrm{D}$ domain. Next, the steady flame is replaced $15 \times$ $\delta_{f}$ from the wall in a corrected velocity field: the laminar flame speed is subtracted to obtain a zero-velocity field in the fresh gas region. After a small transitional time, the flame propagates at its laminar flame speed $s_{L}$ to the wall.

\section{Validation of Laminar Head on Quenching}

The accuracy of the DNS using the complex scheme LU19 is verified by comparison against DNS data from [9] for a laminar, one-dimensional methane-air flame burning at stoichiometry. As in the present study, [9] used two different wall temperatures $T_{w}$ for HOQ (300 and $600 \mathrm{~K})$. The authors of [9] have applied detailed chemical kinetics from [29] using 17 species and 52 reactions. First, the wall heat fluxes normalized by the flame power $q_{f}=\rho_{u} s_{L} c_{p}\left(T_{b}-T_{u}\right)$ are shown (Fig. 3 left). Time has been normalized by the flame time $t_{f}=\delta_{f} / s_{L}$. Good agreement is found for both wall temperatures. Next, the quenching distance is compared in terms of Peclet number $P e=x / \delta_{f}$ that is the wall distance normalized by the thermal flame thickness for the undisturbed laminar flame. The definition of the thermal thickness is $\delta_{f}=\Delta T / \max \left(\frac{\partial T}{\partial x}\right)$ [7]. The flame position is tracked by defining an iso-thermal contour of $T_{i s o}=1900 \mathrm{~K}$. The influence of the iso-thermal contour has been checked on the Peclet number $P e$ and only small deviations are found. Figure 3 right displays the Peclet numbers for the cases $T_{w}=300 \mathrm{~K}$ and $T_{w}=600 \mathrm{~K}$ which are reproducing the reference result with marginal differences as summarized in Table 1. 

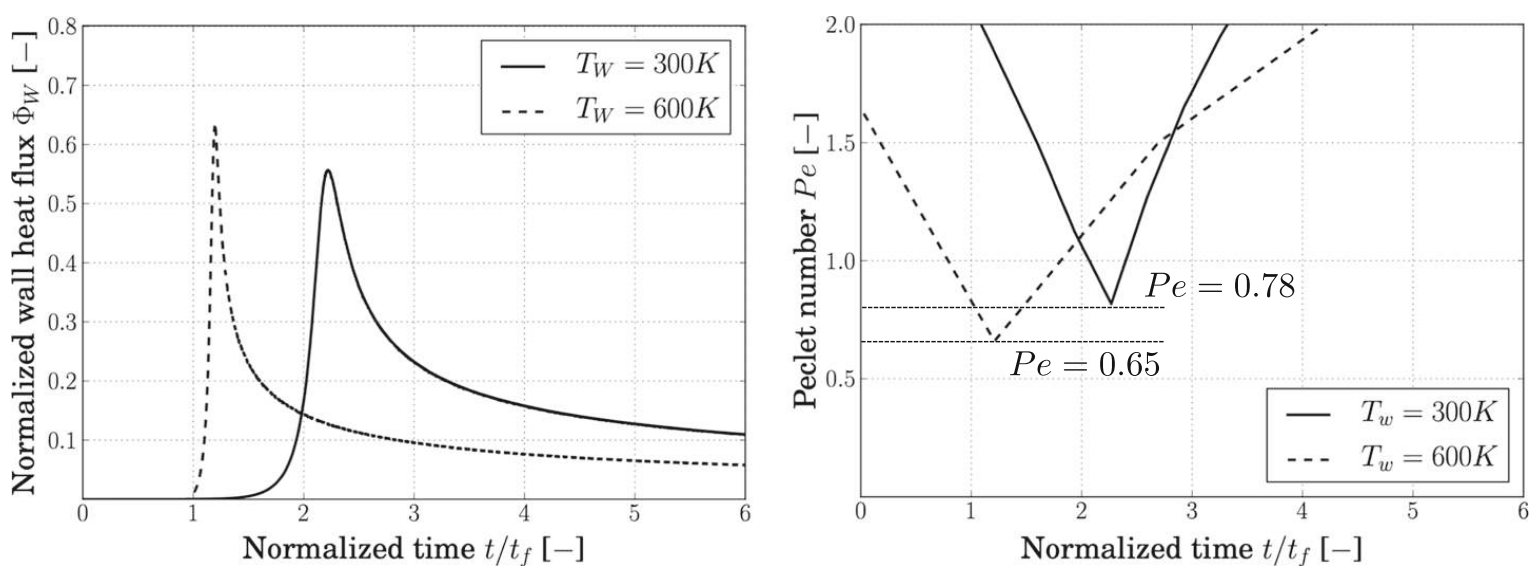

Fig. 3 Left: Normalized wall heat fluxes $\Phi_{w}$. Right: Quenching distances expressed by Peclet numbers $P e$

\section{Laminar Head on Quenching: Direct Combustion Noise Generation}

\subsection{Wall temperature}

In this section, the impact of equivalence ratio and wall temperature on the noise generation is examined. The time traces of pressure fluctuations for different equivalence ratios show that the highest sound levels are generated for stoichiometric flames (Fig. 4 left). At stoichiometric conditions, the smallest ratio of $T_{u} / T_{b}$ and the highest laminar flame speed $s_{L}$ is encountered (Eq. 1). The relation between pressure and heat release is evidenced by Fig. 4 right. The generated sound depends on the change of heat release rate, confirming theoretical and experimental observations [17, 19]. As already reported by Popp et al. [9], the heat release rate increases slightly in the presence of the wall before decreasing rapidly to zero. Figure 5 displays the effect of wall temperature on the generated sound. It is assumed, that fresh gases have the same temperature as the wall. For a flame burning at stoichiometry with incoming fresh gases at $T_{u}=300 \mathrm{~K}$ the sound generated is around $380 \mathrm{~Pa}$. At stoichiometric conditions the highest pressure fluctuations are observed where laminar flame speed and adiabatic temperatures are also at maximum. Good agreement is found between DNS and the model of Eq. 1. Note that all pressure fluctuations are one-dimensional and propagate in the burnt gases at sound speed towards the outlet.

\subsection{High pressure}

Since realistic combustors operate at high pressures, it is interesting to see the effect of high pressure on the generation of noise. Pressure fluctuations are recorded for chamber

Table 1 Comparison of normalized wall heat flux $\Phi_{w}$ and Peclet number $P e$ of present simulations using the complex scheme LU19 with laminar HOQ DNS from [9]

\begin{tabular}{llll}
\hline$T_{w}[K]$ & & Present study & Popp \& Baum [9] \\
\hline 300 & $\Phi_{w}$ & 0.55 & 0.54 \\
& $P e$ & 0.78 & 0.70 \\
600 & $\Phi_{w}$ & 0.63 & 0.68 \\
& $P e$ & 0.65 & 0.62
\end{tabular}



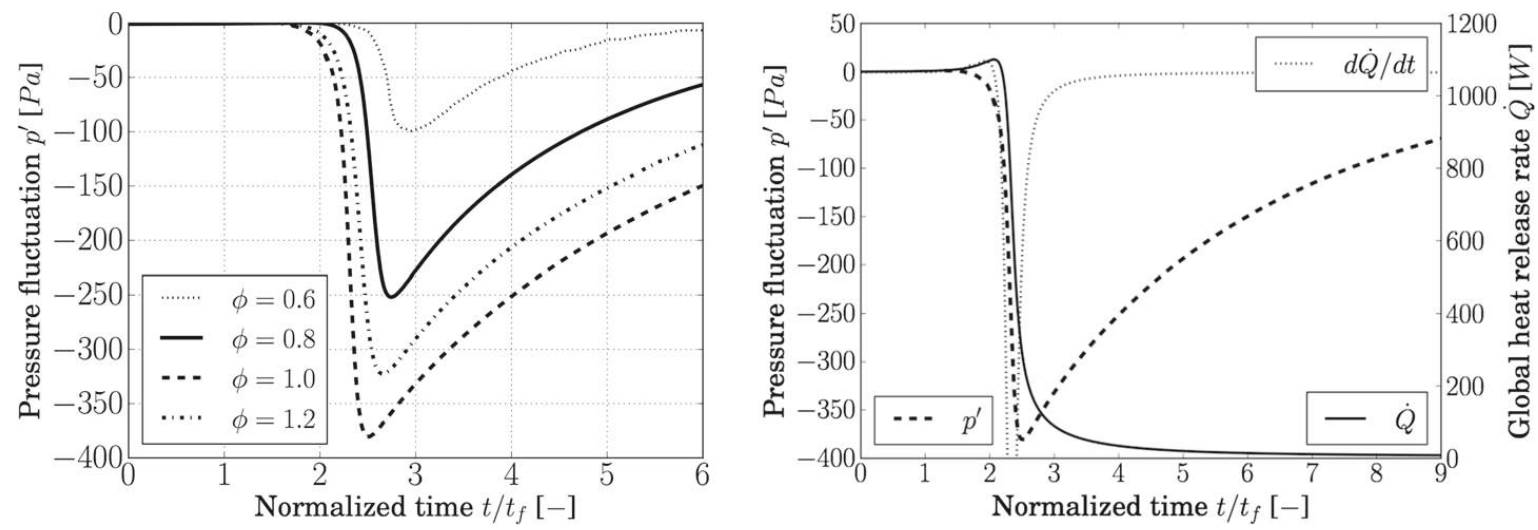

Fig. 4 Left: Pressure fluctuation profiles for the different equivalent ratios $\phi$ recorded at probe $P_{f f}$. The wall temperature is $T_{w}=300 \mathrm{~K}$ for all equivalence ratios. Right: Evolution of pressure fluctuation, global heat release and the rate of change of the heat release for the stoichiometric flame using complex chemistry

pressures at 1, 5 and 10 bar (Fig. 6). As expected, the pressure fluctuations increase for higher pressures. The ratio of chamber pressure to pressure fluctuation during HOQ events is not linear: assuming linearity, pressure fluctuations for 10 bar would reach $3800 \mathrm{~Pa}$. High pressures lead to lower pressure fluctuations which are correctly captured by the model of Eq. 1.

Global heat release rates $\dot{Q}^{\prime}$ during HOQ are plotted for 1, 5 and 10 bar in Fig. 7. Higher pressure generation levels are in correlation with the rate of change in the global heat release rate. For higher chamber pressures the gradient of $\dot{Q}^{\prime}$ becomes steeper and thus causes the higher noise level.

\subsection{Lewis number}

Fuel mixtures of $\mathrm{CH}_{4} / \mathrm{H}_{2}$ have become a possible path for future combustion since they are characterized by wider flammability limits, higher strain resistance and possibly lower $C O$ concentrations [30]. Here, we will investigate its impact on HOQ noise generation. First,

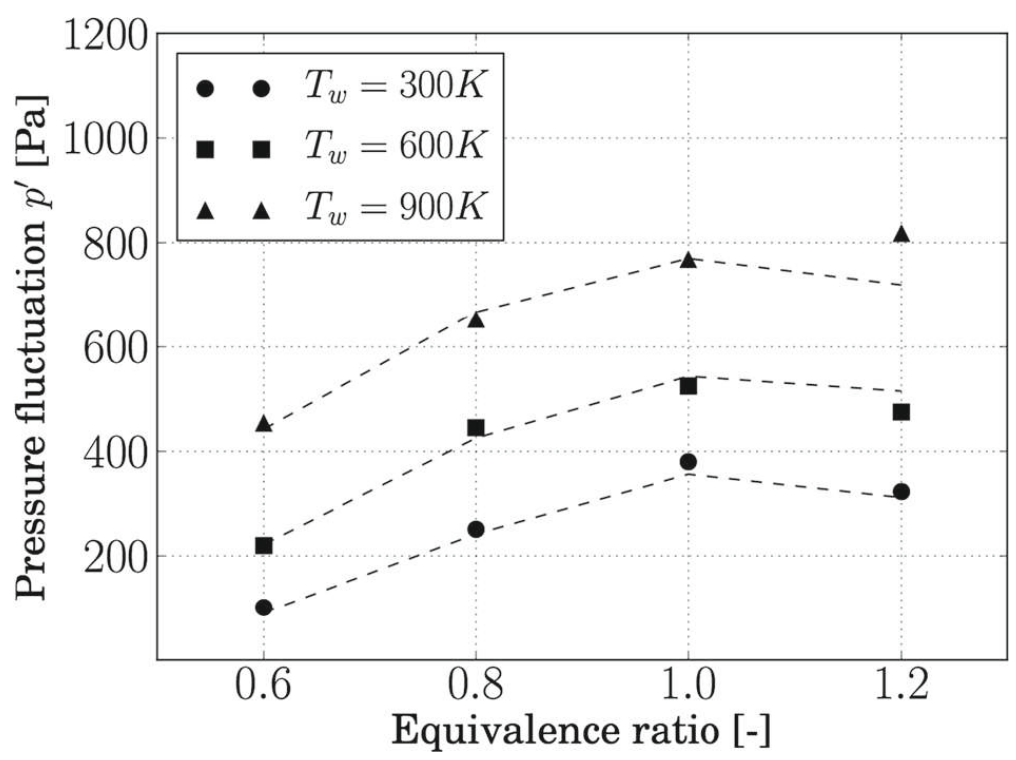

Fig. 5 Effect of wall temperature on the generated sound. Pressure recorded at probe $P_{f f}$. Dashed lines depict the model in Eq. 1 


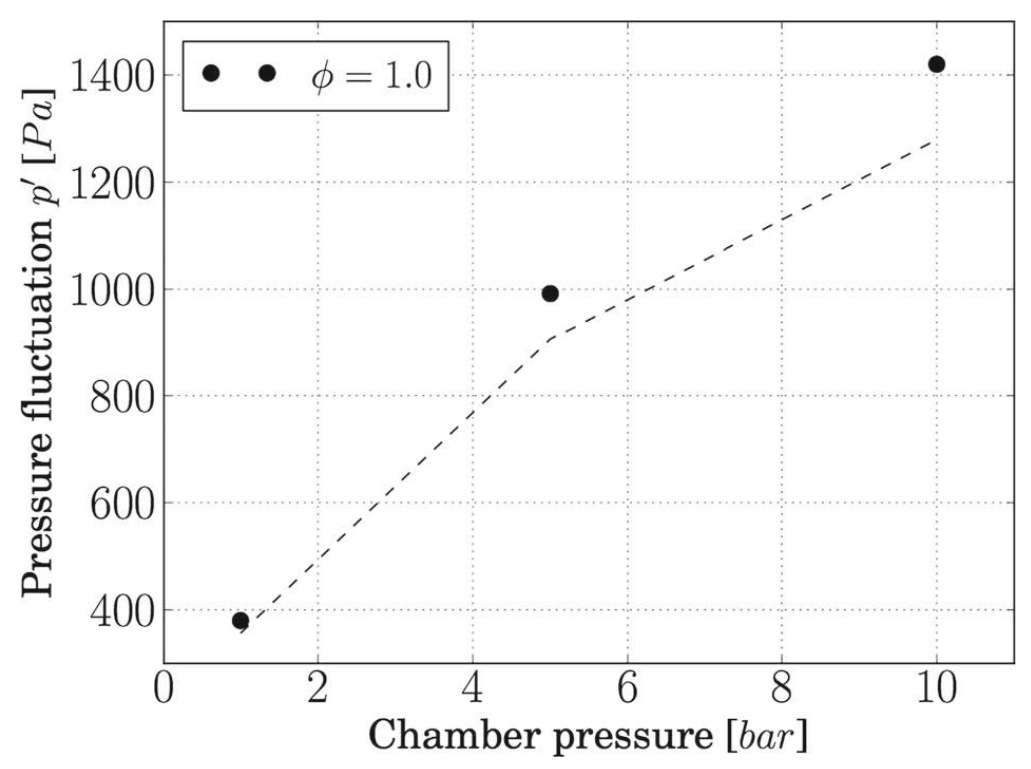

Fig. 6 Effect of chamber pressure on the generated sound. Dashed lines depict the model in Eq. 1

following Dinkelacker et al. [31], an effective Lewis $L e^{*}$ number can be determined by:

$$
\frac{1}{L e^{*}}=\frac{\chi_{C H_{4}}}{L e_{C H_{4}}}+\frac{\chi_{H_{2}}}{L e_{H_{2}}}
$$

where $\chi_{\mathrm{CH}_{4}}$ and $\chi_{\mathrm{H}_{2}}$ denote the volumetric fractions of the fuel. Table 2 summarizes the effective Lewis numbers for the stoichiometric flame.

The sound generated for these mixtures is displayed in Fig. 8. The addition of $\mathrm{H}_{2}$ does not affect the generated pressure fluctuations much. For mixtures up to $20 \%$ of $\mathrm{H}_{2}$ addition, the fluctuations remain constant and increase for the stoichiometric case when $30 \%$ of $\mathrm{H}_{2}$ is used, which is the highest Lewis number analyses here. The generated sound is correctly predicted by Eq. 1 .

The quasi-constant sound level is confirmed by the temporal evolution of the global heat release. As already pointed out in the foregoing sections, the pressure levels depend on

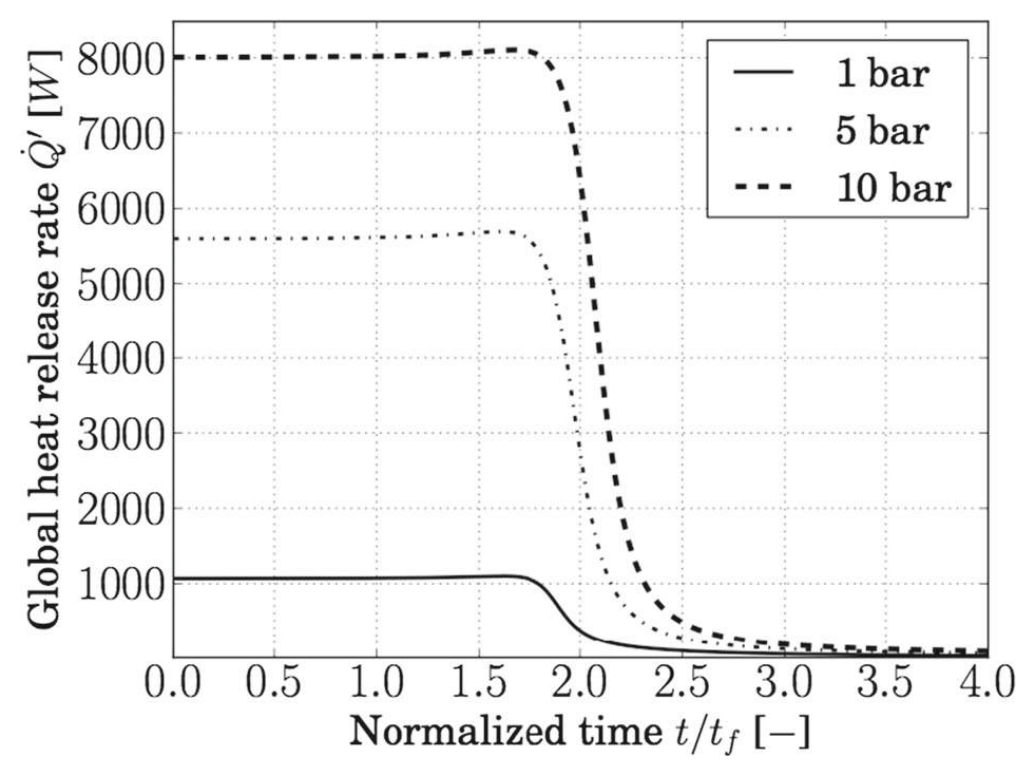

Fig. 7 Effect of chamber pressure on the rate of change of the global heat release $\dot{Q}^{\prime}$ 
Table 2 Effective Lewis numbers $L e^{*}$ for different fuel mixtures of $\mathrm{CH}_{4} / \mathrm{H}_{2}$ following Eq. 2 of [31]

\begin{tabular}{lllll}
\hline $\mathrm{CH}_{4}$ content [\%] & 100 & 90 & 80 & 70 \\
\hline$L e^{*}[-]$ & 1.0345 & 1.2675 & 1.4934 & 1.7088 \\
\hline
\end{tabular}

the rate of change of the heat release. Figure 9 indicates a similar rate of change of the global heat release resulting in similar pressure fluctuation levels. Note, that the effect of Lewis number on the production of sound due to flame-flame annihilation was examined by Jimenez et al. [32] for hydrogen/air flames. They concluded, that the Lewis number has an impact on the sound generation as shown here for the highest effective Lewis number $L e^{*} \approx$ 1.71. However, pure hydrogen/air flames behave differently to flames using hydrocarbon fuels and should be compared with caution.

\subsection{Chemistry modeling}

The effect of chemistry modeling is investigated in this section by first comparing the heat release profiles at $\phi=1.0$ for three mechanisms: while GRI-MECH and LU19 chemistries agree very well in terms of shape and local values, the simple mechanism (BFER) overestimates the maximum local heat release by $25 \%$ for the stoichiometric case (Fig. 10 right). Additionally, reaction takes place later resulting in a marginal spatial shift. Nevertheless, all mechanisms agree well in laminar flame speed $\left(s_{L}=0.379 \mathrm{~m} / \mathrm{s}\right.$ for the complex mechanism and $s_{L}=0.377 \mathrm{~m} / \mathrm{s}$ for the simple mechanism) since it is the integral of the heat release profile. Similar trends are observed for the lean case $\phi=0.6$ but with a smaller error in the maximum local heat release (about $15 \%$, not shown here).

Simulations are performed for a range of equivalent ratios and resulting pressure fluctuations are plotted for both chemistries (Fig. 11). In the leanest case $(\phi=0.6)$ the resulting pressure fluctuations are close to those predicted by the complex scheme. For the other cases, HOQ sound generation is overpredicted for the simple mechanism. Figure 10 right

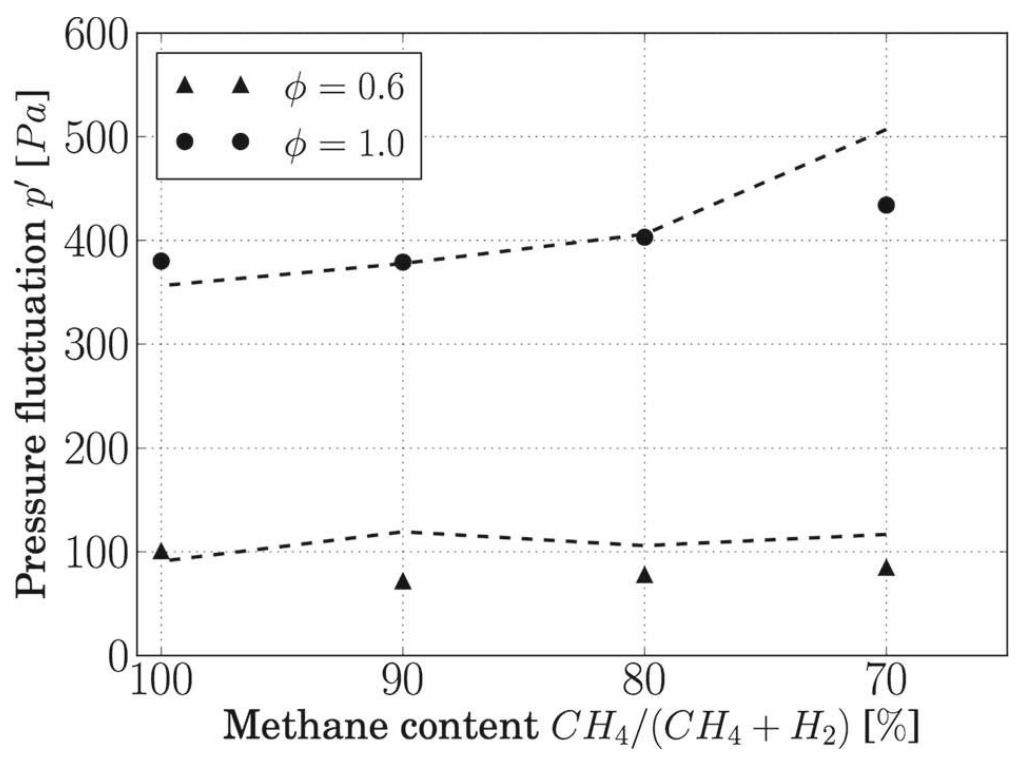

Fig. 8 Effect of $\mathrm{H}_{2}$ addition to the fuel mixture on the generated sound. Dashed lines depict the model in Eq. 1 


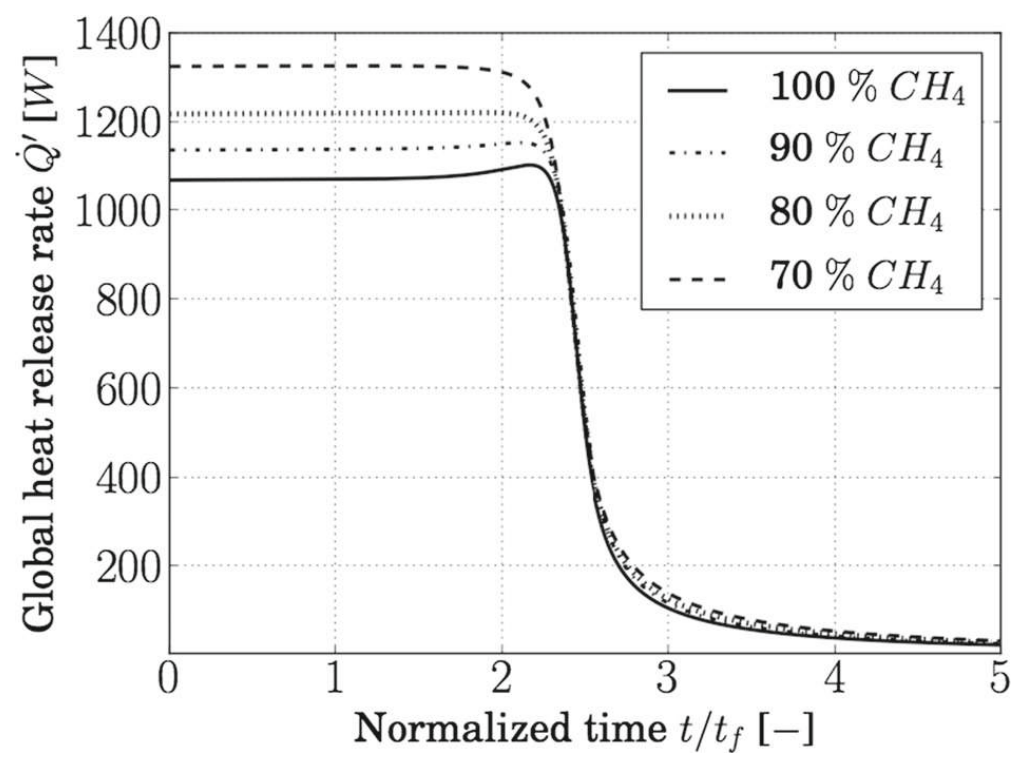

Fig. 9 Effect of Lewis number on temporal evolution of the global heat release rate $\dot{Q}^{\prime}$
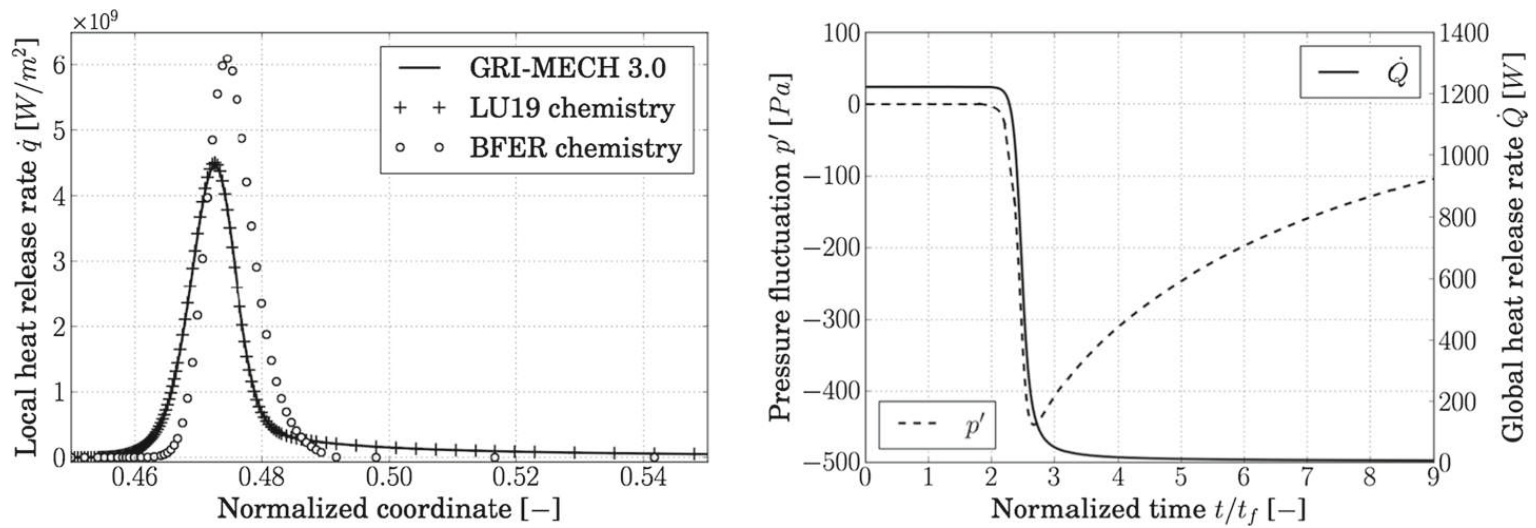

Fig. 10 Left: Comparison of full, complex and simple chemistry for a one-dimensional, stoichiometric flame computed with CANTERA. Right: Evolution of pressure fluctuation and global heat release for the stoichiometric flame using simple chemistry

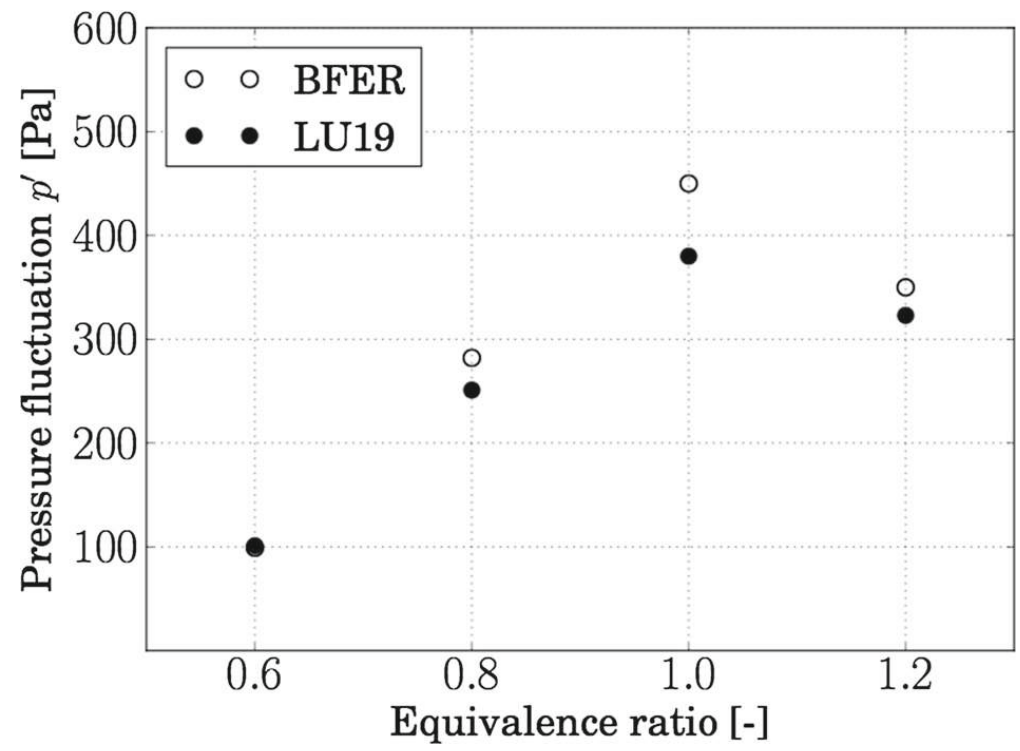

Fig. 11 Effect of chemistry modeling on the generated sound 

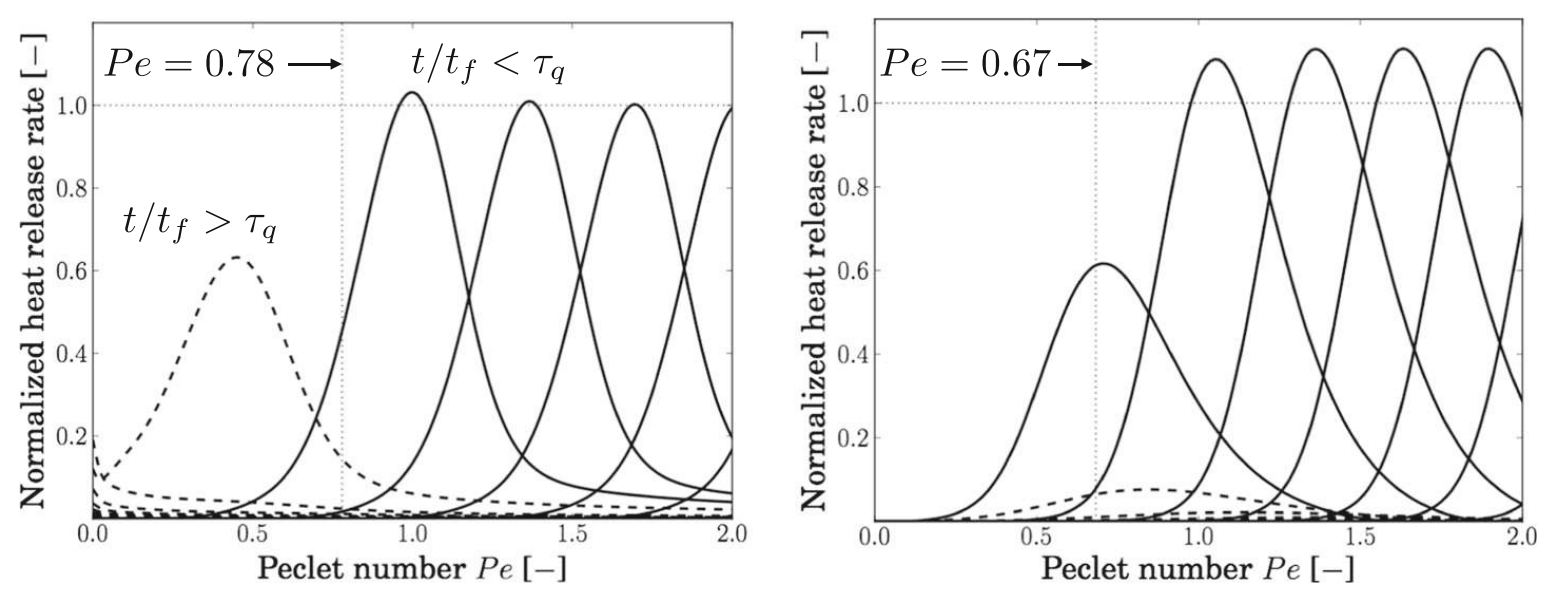

Fig. 12 Comparison of normalized heat release profiles plotted before (continuous lines) and after (dashed lines) flame quenching. Profiles are normalized by maximum heat release from undisturbed flame obtained with full chemistry. Left: HOQ for complex chemistry. Right: HOQ for simple chemistry

displays the evolutions of pressure and global heat release for the stoichiometric case. Comparing to the results for the complex mechanism (Fig. 4 right), again a somehow linear behavior is observed between these quantities. The global heat release for the simple chemistry decreases rapidly in one flame time. The complex scheme indicated nearly three flame times until the heat release rate extinguishes. The maximum pressure fluctuation is around $450 \mathrm{~Pa}$ and is about $70 \mathrm{~Pa}$ higher than for the complex scheme. Interestingly, the rise of the global heat release in the vicinity of the wall is not captured by the simple chemistry. Since the wall heat fluxes between simple and complex schemes are very similar and the simple scheme reproduces the correct laminar flame speed, the difference on the generated sound can be explained by the local values of heat release. In particular, the 'pressure peak error' of about $15 \%$ can be mainly caused by the error in maximum heat release. Note that errors in the local heat release rate (in the order of $15 \%$ ) for the flame at $\phi=0.6$ leads to very similar pressure fluctuations for the simple and the complex chemistry (pressure peak error of about $2 \%$ ). Figure 12 compares the heat release profiles at times before and after flame quenching $\left(\tau_{q}\right)$ for the complex (left) and simple (right) chemistry. The simple scheme features a complete extinction of the flame at $P e=0.67$ while the complex scheme indicates heat release rates still reaching $60 \%$ of the maximum value. These results are linked with
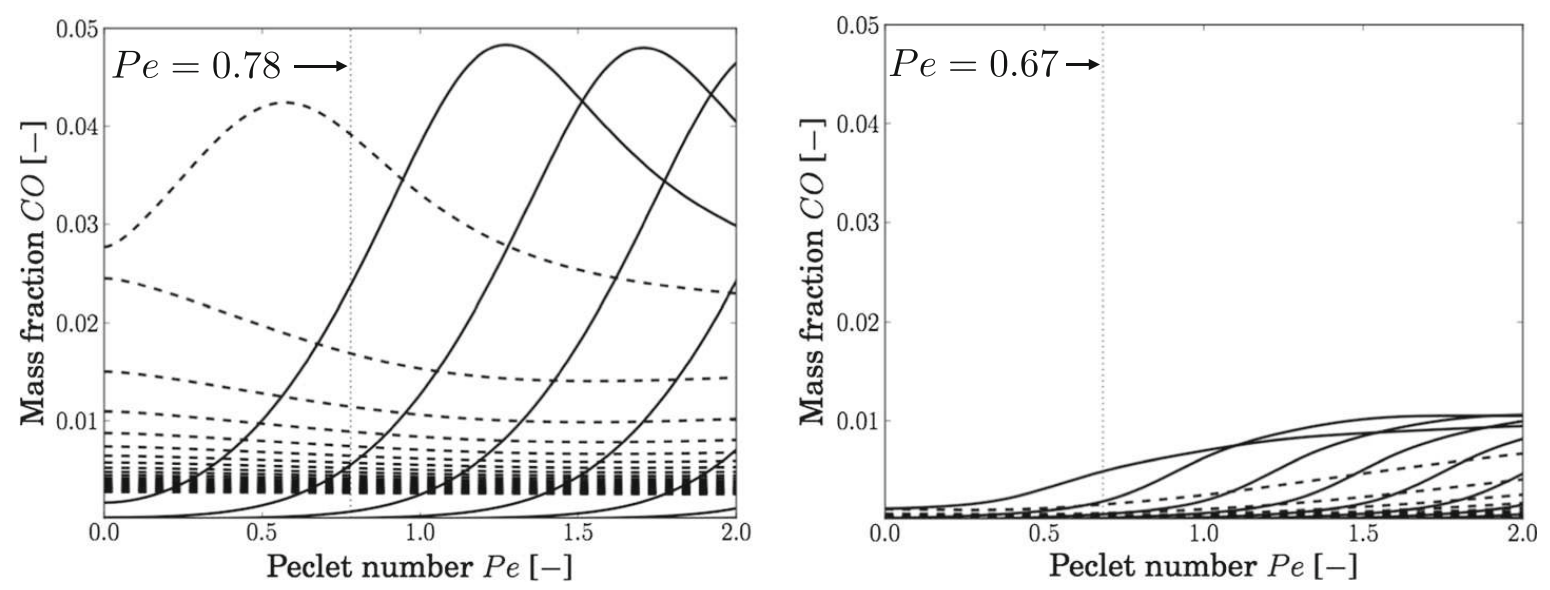

Fig. 13 Comparison of $C O$ mass fraction profiles plotted before (continuous lines) and after (dashed lines) flame quenching. Left: HOQ for complex chemistry. Right: HOQ for simple chemistry 
the profiles of the $C O$ species (Fig. 13) where the simple mechanism (right) underpredicts the concentration compared to the complex scheme. The production of $C O$ is an endothermic process and is described within the simple mechanism by the first of two reactions, not taking into account the production and destruction of minor and intermediate species. Due to this simplification, the heat release rates decrease faster in time and lead finally to higher pressure fluctuations.

\section{Conclusion}

The generation of pressure fluctuations has been investigated for laminar head on quenching. High-fidelity numerical simulations are performed over a range of equivalence ratios for various scenarios (wall temperature, Lewis number, chamber pressure) and exhibited high levels of direct combustion noise. It has also been shown that the theory developed by Talei et al. [17] for flame annihilation reproduces the numerical results and can easily be used for sound level estimations. This confirms that the mechanism of flame surface destruction is the leading mechanism for sound generation during HOQ. The sound level was found to depend on the rate of change of the global heat release rate. In a next step, chemistry modeling has been identified as a possible source of error in the generation of sound during HOQ: simple chemical kinetics feature higher pressure fluctuation amplitudes than complex schemes and theoretical results. While the error remains small for lean cases (about 2\%), conditions near stoichiometry show pressure amplitude errors in the order of $15 \%$. Since the chemical path of species production and destruction for the simple scheme is truncated, the temporal evolution (rate of change) of heat release rate is not correctly reproduced and can lead to erroneous pressure fluctuations.

Acknowledgments The research leading to these results has received funding from the European Research Council under the European Union's Seventh Framework Programme (FP/2007-2013)/ERC Grant Agreement ERC-AdG 319067-INTECOCIS. This work was granted access to the high-performance computing resources of IDRIS under the allocation x20162b7036 made by GENCI. Cerfacs is greatly acknowledged for their support on the AVBP code. A.G. would like to thank O. Schulz, Dr. P. Xavier and Dr. C. Kraus for fruitful discussions.

\section{Compliance with Ethical Standards}

Conflict of interests The authors declare that they have no conflict of interest.

\section{References}

1. Dreizler, A., Böhm, B.: Advanced laser diagnostics for an improved understanding of premixed flamewall interactions. Proc. Combust. Inst. 35, 37-64 (2015). doi:10.1016/j.proci.2014.08.014

2. Gruber, A., Sankaran, R., Hawkes, E.R., Chen, J.: Turbulent flame-wall interaction: A direct numerical simulation study. J. Fluid Mech. 658, 5-32 (2010). doi:10.1017/S0022112010001278

3. Hocks, W., Peters, N., Adomeit, G.: Flame quenching in front of a cold wall under two-step kinetics. Combust. Flame 41, 81-99 (1981). doi:10.1016/0010-2180(81)90049-3

4. Wichman, I., Bruneaux, G.: Head on quenching of a premixed flame by a cold wall. Combust. Flame 103(4), 296-310 (1995). doi:10.1016/0010-2180(95)00100-X

5. Xavier, P., Ghani, A., Mejia, D., Miguel-Brebion, M., Bauerheim, M., Selle, L., Poinsot, T.: Experimental and numerical investigation of flames stabilised behind rotating cylinders: interaction of flames with a moving wall. J. Fluid Mech. 813, 127-151 (2017)

6. Lieuwen, T.: Unsteady Combustor Physics. Cambridge University Press (2012) 
7. Poinsot, T., Veynante, D.: Theoretical and Numerical Combustion, 3rd edn, (www.cerfacs.fr/elearning) (2011)

8. Bruneaux, G., Akselvoll, K., Poinsot, T., Ferziger, J.: Flame-wall interaction in a turbulent channel flow. Combust. Flame 107(1/2), 27-44 (1996). doi:10.1016/0010-2180(95)00263-4

9. Popp, P., Baum, M.: An analysis of wall heat fluxes, reaction mechanisms and unburnt hydrocarbons during the head-on quenching of a laminar methane flame. Combust. Flame 108(3), 327-348 (1997). doi:10.1016/S0010-2180(96)00144-7

10. Westbrook, C.K., Adamczyk, A.A., Lavoie, G.A.: A numerical study of laminar flame wall quenching. Combust. Flame 40, 81-99 (1981). doi:10.1016/0010-2180(81)90112-7

11. Ihme, M.: Combustion and engine-core noise. Ann. Rev. Fluid Mech 49, 277-310 (2017). doi:10.1146/annurev-fluid-122414-034542

12. Franzelli, B., Riber, E., Sanjosé, M., Poinsot, T.: A two-step chemical scheme for LargeEddy Simulation of kerosene-air flames. Combust. Flame 157(7), 1364-1373 (2010). doi:10.1016/j.combustflame.2010.03.014

13. Ghani, A., Poinsot, T., Gicquel, L., Staffelbach, G.: Les of longitudinal and transverse self-excited combustion instabilities in a bluff-body stabilized turbulent premixed flame. Combust. Flame 162, 4075$4083(2015)$

14. Hermeth, S., Staffelbach, G., Gicquel, L., Poinsot, T.: LES evaluation of the effects of equivalence ratio fluctuations on the dynamic flame response in a real gas turbine combustion chamber. Proc. Combust. Inst. 34(2), 3165-3173 (2013). doi:10.1016/j.proci.2012.07.013. http://www.sciencedirect.com/science/ article/pii/S1540748912003045

15. Ghani, A., Gicquel, L., Poinsot, T.: Acoustic analysis of a liquid fuel swirl combustor using dynamic mode decomposition. In: ASME Turbo Expo 2015: Turbine Technical Conference and Exposition, pp. 1-9. American Society of Mechanical Engineers (2015)

16. Ghani, A., Poinsot, T., Gicquel, L., Müller, J.D.: Les study of transverse acoustic instabilities in a swirled kerosene/air combustion chamber. Flow Turb. Combust. 96(1), 207-226 (2016)

17. Talei, M., Brear, M.J., Hawkes, E.R.: Sound generation by laminar premixed flame annihilation. J. Fluid Mech. 679, 194-218 (2011). doi:10.1017/jfm.2011.131

18. Brear, M.J., Nicoud, F., Talei, M., Giauque, A., Hawkes, E.R.: Disturbance energy transport and sound production in gaseous combustion. J. Fluid Mech. 707, 53-73 (2012). doi:10.1017/jfm.2012.264

19. Candel, S., Durox, D., Schuller, T.: Flame interactions as a source of noise and combustion instabilities. In: 10th AIAA/CEAS Aeroacoustics Conference - AIAA 2004-2928, pp. 1444-1454 (2004)

20. Blanchard, M., Schmid, P.J., D.S., Schuller, T.: Pressure wave generation from perturbed premixed flames. J. Fluid Mech. 797, 231-246 (2016). doi:10.1017/jfm.2016.268

21. Strahle, W.C.: On combustion generated noise. J. Fluid Mech. 49, 399-414 (1971). doi:10.1017/S0022112071002167

22. Swaminathan, N., Xu, G., Dowling, a.P., Balachandran, R.: Heat release rate correlation and combustion noise in premixed flames. J. Fluid Mech. 681, 80-115 (2011). doi:10.1017/jfm.2011.232

23. Lighthill, M.J.: On sound generated aerodynamically: I. general theory. Proc. R. Soc. Lond 211(1107), 564-587 (1952). doi:10.1098/rspa.1952.0060

24. Crighton, D.G., Dowling, A.P., Williams, J.E.F., Heckl, M., Leppington, F.: Modern Methods in Analytical Acoustics, Lecture Notes, vol. 1sd ed. Springer Verlag, New-York (1992)

25. Colin, O., Ducros, F., Veynante, D., Poinsot, T.: A thickened flame model for large eddy simulations of turbulent premixed combustion. Phys. Fluids 12(7), 1843-1863 (2000). doi:10.1063/1.870436

26. Poinsot, T., Lele, S.: Boundary conditions for direct simulations of compressible viscous flows. J. Comput. Phys. 101(1), 104-129 (1992). doi:10.1016/0021-9991(92)90046-2

27. Lu, T., Law, C.K.: A criterion based on computational singular perturbation for the identification of quasi steady state species: A reduced mechanism for methane oxidation with no chemistry. Combust. Flame 154, 761-774 (2008). doi:10.1016/j.combustflame.2008.04.025

28. Bodenstein, M.: Eine Theorie der photochemischen Reaktionsgeschwindigkeiten. Z. Phys. Chem. 85(329), 0022-3654 (1913)

29. Warnatz, J.: The mechanism of high temperature combustion of propane and butane. Combust. Sci. Tech. 34, 177 (1983). doi:10.1080/00102208308923692

30. Hawkes, E.R., Chen, J.H.: Direct numerical simulation of hydrogen-enriched lean premixed methane-air flames. Combust. Flame 138(3), 242-258 (2004). doi:10.1016/j.combustflame.2004.04.010

31. Dinkelacker, F., Manickam, B., Muppala, S.: Modelling and simulation of lean premixed turbulent methane/hydrogen/air flames with an effective lewis number approach. Combust. Flame 158, 1742-1749 (2011). doi:10.1016/j.combustflame.2010.12.003

32. Jimenez, C., Haghiri, A., Brear, M.J., Talei, M., Hawkes, E.: Sound generation by premixed flame annihilation with full and simple chemistry. Proc. Combust. Inst. 35, 3317-3325 (2015) 